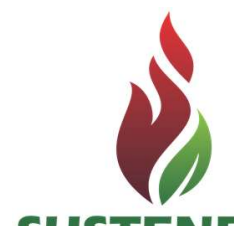

SUSTENERE

Publishing Corporation

\section{BIOQUÍMICA DA RELAÇÃO PATÓGENO-HOSPEDEIRO: A IMPORTÂNCIA BIOLÓGICA, FUNCIONAL E ESTRUTURAL DO MICRONUTRIENTE COBRE PARA O CRESCIMENTO E INFECÇÃO POR FUNGOS PATOGÊNICOS}

\section{RESUMO}

Os íons metálicos são elementos vitais que participam de inúmeros processos metabólicos em todos os tipos celulares, sendo ligados diretamente ao metabolismo do DNA e ao processamento pós-traducional da maioria das proteínas. Em microorganismos patogênicos os íons metálicos ainda garantem uma colonização bemsucedida do parasita no hospedeiro. Dessa forma, é de extrema importância para o bom funcionamento celular que haja tanto a distribuição correta dos metais, quanto sua devida concentração, nos compartimentos intracelulares, já que aparentemente qualquer distúrbio na concentração de íons metálicos em meio intracelular pode causar danos a elementos metabólicos vitais, geralmente acarretando morte celular.

PALAVRAS-CHAVES: Homeostase de Cobre; Mecanismos Moleculares; Fungos Patogênicos.

\section{BIOCHEMISTRY OF THE HOST-PATHOGEN \\ INTERACTIONS: THE BIOLOGICAL IMPORTANCE, FUNCTIONAL AND STRUCTURAL OF THE MICRONUTRIENT COPPER FOR THE GROWTH AND INFECTION BY PATHOGENIC FUNGI}

\section{ABSTRACT}

Metal ions are vital elements involved in many metabolic processes in all cell types, being directly related to DNA metabolism and post-translational processing of most proteins. In pathogenic microorganisms metal ions still guarantee a successful colonization of the parasite in the host. Thus, it is of utmost importance for proper cell function so that there is the correct distribution of the metals, as their proper concentration in intracellular compartments, since apparently no disturbance in the concentration of metal ions in the intracellular environment can damage the elements vital metabolic usually resulting in cell death.

KEYWORDS: Copper Homeostasis; Molecular Mechanisms; Pathogenic Fungi.
Scire Salutis, Aquidabã, v.5, n.1, Out, Nov, Dez 2014, Jan, Fev, Mar, Abr, Mai, Jun, Jul, Ago, Set, Out

2015.

ISSN 2236-9600

SECTION: Articles

TOPIC: Medicina Tropical

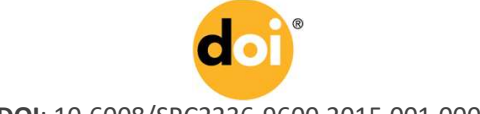

DOI: 10.6008/SPC2236-9600.2015.001.0002

\section{Rodrigo da Silva Santos \\ Universidade de São Paulo, Brasil http://lattes.cnpq.br/4806187026900959 rdssantos@gmail.com}

Danilo Candido de Almeida Universidade Federal de São Paulo, Brasil http://lattes.cnpq.br/8395461764493766

Aline Helena da Silva Cruz

Universidade de São Paulo, Brasil http://lattes.cnpq.br/1273137151063484

Received: 07/03/2015

Approved: 23/08/2015

Reviewed anonymously in the process of blind peer.

\section{Referencing this:}

SANTOS, R. S.; ALMEIDA, D. C. CRUZ, A. H.S. Bioquímica da relação patógeno-hospedeiro: a importância biológica, funcional e estrutural do micronutriente cobre para o crescimento e infecção por fungos patogênicos. Scire Salutis, Aquidabã, v.5, n.2, p.14-23, 2015. DOI:

http://dx.doi.org/10.6008/SPC22369600.2015 .001 .0002 


\section{INTRODUÇÃO}

Os metais são cofatores para inúmeras enzimas e exercem papel estrutural em um grande número de proteínas. Entretanto, estes metais podem ser tóxicos, se os níveis de captação e distribuição não forem regulados, uma vez que o excesso pode comprometer as funções celulares, gerando radicais livres, que são altamente destrutivos para as células (PEÑA et al., 2000; THEIL e EISENSTEIN, 2000; EIDE, 2003). Portanto, os organismos devem manter as concentrações citoplasmáticas de cobre, ferro e zinco, que são micronutrientes essenciais, em níveis não tóxicos, para que esses metais sejam apenas suficientes para o crescimento celular e participação em processos metabólicos vitais. Dentre os mecanismos homeostáticos já identificados e estudados, incluem-se o controle da transcrição de genes envolvidos na aquisição, distribuição e armazenamento desses metais (RUTHERFORD e BIRD, 2004).

A levedura Saccharomyces cerevisiae tem sido utilizada como organismo modelo eucariótico para os estudos dos mecanismos de regulação do transporte dos micronutrientes cobre, ferro e zinco. Estudos têm demonstrado que a captação de metais é mediada por dois sistemas de transportes específicos. Um sistema de alta afinidade, que é ativo em condições limitantes dos respectivos metais, o qual é regulado por fatores transcricionais metais-responsivos, que aumentam a expressão dos genes de transportadores quando as quantidades dos respectivos metais são limitadas. Um sistema de baixa afinidade também ocorre e continua ativo, desempenhando sua função para manutenção da célula, mesmo quando a quantidade do metal é mais abundante. Estudos em S. cerevisiae identificaram um grande número de famílias de genes que atuam no transporte de metais, os quais apresentam homólogos que desempenham funções relacionadas nestes processos em mamíferos e vegetais (VAN HO et al., 2002). A disponibilidade de cobre, ferro e zinco em tecidos vivos é mantida em níveis baixos o suficiente para restringir o crescimento de agentes patogênicos. Por exemplo, o corpo humano adulto contém aproximadamente $4,0 \mathrm{~g}$ de ferro, de 3 a $5 \mathrm{~g}$ de cobre e 2,3g de zinco (PAPANIKOLAOU e PANTOPOULOS, 2005).

Além dos mecanismos de captação externa dos metais, pode ocorrer uma captação intracelular, isso porque estudos vêm demonstrando a importância da autofagia em diversos processos biológicos, que vão além da adaptação, diferenciação e desenvolvimento celular. $O$ envolvimento mais conhecido e bem descrito do processo de autofagia é no que se refere ao controle da homeostase de metais, visando à adaptação das células a nutrientes específicos e/ou na sobrevivência do organismo em condições de estresse (ONODERA e OHSUMI, 2005). Já sendo demonstrado, por exemplo, que quando o fungo filamentoso Aspergillus fumigatus é cultivado na ausência de metais, mimetizando as condições do hospedeiro durante o processo infectivo, apresenta deficiência no seu crescimento, condição em que o fungo passa a realizar processos autofágicos, reciclando proteínas associadas a metais pré-existentes. Dessa maneira ocorre a liberação de íons metálicos, deixando-os livres para utilização em processos metabólicos necessários para o crescimento do fungo e restabelecimento da homeostase da célula fúngica. Vale 
ressaltar que quando são acrescentados os metais zinco, ferro, manganês, magnésio e cobre aos meios de cultura pobres em micronutrientes, o crescimento do microrganismo é normalizado (RICHIE e ASKEW, 2008).

Nesse sentido, o objetivo desse estudo é descrever as relações bioquímicas e moleculares existentes entre a homeostase de cobre, ferro e outros micronutrientes, na tentativa de estabelecer o papel dos mesmos, na patogenicidade e sobrevivência dos fungos no microambiente hospedeiro e durante o processo infeccioso.

\section{DISCUSSÃO TEÓRICA}

\section{Homeostase de Cobre}

O cobre é um metal de transição, capaz de atuar entre dois estados redox, $\mathrm{Cu}^{+2}$ oxidado e $\mathrm{Cu}^{+1}$ reduzido. É requerido pela maioria dos organismos como um cofator importante para uma variedade de enzimas que realizam processos biológicos essenciais, tais como: respiração e crescimento celular, aquisição de ferro, proteção contra o estresse oxidativo, pigmentação (melanização) e outros processos biológicos complexos (PUIG et al., 2002). Mas, o cobre em excesso no meio intracelular torna-se tóxico, pois reage com oxigênio, formando o radical livre hidroxil, altamente destrutivo para a célula, causando danos aos lipídios, às proteínas e ao DNA. Consequentemente, os organismos desenvolveram mecanismos para o transporte de cobre na célula, visando manter as concentrações intracelulares em níveis não tóxicos (MARVIN et al., 2003).

Em fungos, uma resposta comum das células às flutuações nos níveis de cobre é reprogramar a transcrição de genes que são importantes para a captura de cobre, de modo a manter as concentrações de cobre dentro dos limites homeostáticos, permitindo que a quantidade do mesmo seja suficiente para servir como cofator e impedindo sua acumulação em níveis citotóxicos (BEAUDOIN et al., 2006). Estudos realizados com cepas mutantes de $S$. cerevisiae permitiram propor um modelo do transporte de cobre de alta afinidade em células eucarióticas. Para o transporte, o cobre encontrado no meio extracelular na forma $\mathrm{Cu}^{2+}$ é reduzido a $\mathrm{Cu}^{+1}$ pelas redutases férricas de superfície celular, Fre1 e Fre2 (GEORGATSOU, et al., 1997; BEAUDOIN et al., 2007). A principal via de transporte desses íons através da membrana é realizada pelas proteínas transportadoras de cobre de alta afinidade (CTR's) (DANCIS, et al., 1994; BEAUDOIN et al., 2007). É sugerido que os transportadores da família CTR possuem três domínios transmembrânicos, sendo que a região amino-terminal extracelular, apresenta duas ou mais regiões ricas em metioninas, conhecidas como motivos "Mets". Estas regiões são organizadas como MxxM ou MxM e existem em número variável dentro da região amino-terminal. A porção carboxi-terminal seria intracelular, rica em aminoácidos carregados e apresentando uma região conservada de resíduos de histidina e cisteína. Um motivo MxxM, existe na segunda região transmembrana dos transportadores de cobre CTR1 e CTR3 de leveduras e mamíferos, sugerindo que o mesmo poderia 
coordenar a entrada de cobre durante transporte intramembranoso. Todas essas características das duas regiões descritas são próprias das proteínas CTR's localizadas na membrana de fungos, vegetais e mamíferos (KIM et al., 2008).

As proteínas transportadoras de alta afinidade da família CTRs, como CTR1, CTR2 e CTR3, são funcionalmente redundantes, porém estruturalmente apresentam pouca homologia em nível de sequência de aminoácidos (BEAUDOIN et al., 2007). São também proteínas integrais de membrana atuando como permeases competentes na captação de cobre na membrana plasmática, visto também que os genes codificantes de CTR1 e CTR3 são similarmente regulados em nível transcricional em resposta as concentrações de cobre no meio intracelular (PEÑA et al., 2000; BEAUDOIN et al., 2006).

Pelo menos um membro da família CTR em S. cerevisiae não está localizado na membrana plasmática e sim em vacúolos, as proteínas CTR2. Foi verificado que quando o cobre encontra-se em excesso no meio intracelular, o transportador CTR2 tem por função armazená-lo em vacúolos, de modo a manter o equilíbrio. Quando acontece o inverso, CTR2 torna-se também necessário, uma vez que é responsável pelo fornecimento de cobre para as cuproenzimas em condições de escassez do metal. Um homólogo ao CTR2, denominado CTR6, foi identificado em Schizosaccharomyces pombe e funcionalmente caracterizado como transportador vacuolar de cobre (BELLEMARE et al., 2002; PETRIS, 2004; REES e THIELE, 2004; REES e THIELE, 2007). Já as proteínas CTR1 e CTR3 estão localizadas na membrana plasmática de $S$. cerevisiae, sendo responsáveis pela captura extracelular de cobre, enquanto CTR2 transporta e armazena o mesmo em vacúolos, sendo importante também para os processos de detoxificação da célula e liberação do íon, durante carência do metal, para as proteínas cobre-dependentes (PETRIS, 2004).

Em S. cerevisae e $S$. pombe também foi demonstrado que o transporte de cobre está intimamente relacionado à proteína CTR3, visto que mutações realizadas em resíduos de cisteína distribuídos ao longo da cadeia polipeptídica e mais concentrados na região carboxi-terminal, inativaram funcionalmente a proteína, ocasionando uma deficiência no nível de cobre no meio intracelular (BEAUDOIN et al., 2006; BEAUDOIN et al., 2007). A substituição de todos os motivos Mets localizados na porção amino-terminal, prejudicou gravemente a captação de cobre através das proteínas CTRs 3, sugerindo que esta região possa servir como ligante do cobre extracelular (PUIG et al., 2002; PETRIS, 2004).

Um fator de transcrição que responde ao cobre (cuf1) e um transportador de cobre (CTR4) foram descritos em Cryptococcus neoformans (WATERMAN et al., 2007). A deleção de cuf1 resulta em redução na atividade da lacase, deficiência no crescimento em meio com baixo teor de cobre e expressão atenuada de CTR4, sob limitação de cobre. Também o mutante cuf1 mostrou disseminação reduzida ao cérebro em modelo murino de criptococose (WATERMAN et al., 2007). Experimentos com microarranjos de DNA também indicam que genes para a homeostase de cobre podem ser controlados pela rede regulatória de ferro em C. neoformans (JUNG et al., 2006). 


\section{Captação de Cobre por Fungos Patogênicos}

Os patógenos devem competir por níveis reduzidos de nutrientes quando atingem os tecidos do hospedeiro, de modo a desempenhar com sucesso o processo infectivo. Apesar de ferro e cobre terem sido bem caracterizados como fatores determinantes na virulência bacteriana e fúngica, estudos recentes indicam que os metais exercem um papel crítico e fundamental como determinantes para a virulência de fungos como C. neoformans e Candida albicans, durante o estabelecimento da infecção. Em camundongos infectados com cepas de $C$. neoformans mutantes para o gene cuf1 não foram capazes de estabelecer a meningite, porque a transcrição do transportador de cobre CTR4 foi suprimida e o cérebro é um tecido onde os níveis do metal são baixos (WATERMAN, 2007; KIM et al., 2008).

No fungo $C$. albicans têm-se descrito que o mecanismo para regulação da captação de cobre tem se distinguido do já anteriormente proposto para $S$. cerevisiae. Ambos os organismos apresentam o fator de transcrição Mac1p, responsável pela ativação da transcrição do transportador de cobre de alta afinidade CTR1. Em C. albicans CaMac1p é auto-regulado por níveis de cobre, ao contrário do gene Mac1p de S. cerevisiae que é constitutivamente transcrito. Também foi descrito a presença de regiões CUREs (elementos de resposta ao cobre) nas sequências de Cactr1 e CaMac1, regiões essas responsáveis pela identificação dos níveis do metal presentes no meio intracelular. CaMac1p também foi descrito como fator envolvido na regulação da transcrição ferroresponsiva (MARWIN et al., 2003; MARWIN et al., 2004; WOODACRE et al., 2008).

O modelo da via de captação, distribuição, armazenamento e utilização de cobre, proposto por Kim e colaboradores (2008), para C. neoformans, provavelmente é o mesmo para outros fungos, assim como para vegetais e mamíferos. O cobre presente no meio extracelular $\left(\mathrm{Cu}^{+2}\right)$ e reduzido pelas redutases FRE para $\mathrm{Cu}^{+1}$ e transportado pelas proteínas de alta afinidade CTRs. No meio intracelular o cobre, poderá ser captado pela metalochaperona ATX1 que o transporta até a proteína CCC2 (Cu+ATPase), que em S. cerevisae entrega o cobre à via secretória e participa provavelmente nos processos de detoxificação da célula, se dirigindo até o vacúolo onde é acumulado o excesso de cobre. CCC2 também se localiza na membrana do Aparato de Golgi, sendo assim responsável pela distribuição de íons cobre que serão incorporados à cobreproteínas/cuproenzimas recém-sintetizadas. A multicobre ferroxidase FET3 $\left(\right.$ Ferro- $\mathrm{O}_{2-}$ oxidoredutase 3 ) atua conjuntamente com a proteína FET1; as duas são responsáveis pelo transporte de íons ferro reduzidos através da membrana plasmática em S. cerevisiae.

Por esse motivo, existe uma intrincada associação entre o mecanismo de captura de ferro e a disponibilidade de cobre. Outro processo importante está relacionado com a detoxificação de cobre na célula. Em S. cerevisiae o principal mecanismo é mediado pelo produto do gene Cup1, que codifica uma metalotioneína que sequestra esse íon no interior da célula e permite que essa resista a níveis mais altos de cobre (HAMER, et al., 1985). Outro mecanismo descrito para suportar 
altos níveis de cobre no ambiente intracelular está relacionado com o armazenamento desse íon em organelas, conforme descrito em S. pombe (HAMER, 1986).

\section{A Influência do Cobre na Proteção Contra Danos Intracelulares}

Para garantir a homeostase celular e proteger contra danos oxidativos, os organismos aeróbicos apresentam alguns sistemas de defesa antioxidante enzimáticos (peroxidases, superóxido dismutases e catalases) que reagem com as ROS (espécies reativas de oxigênio) e impedem que estas promovam a oxidação dos componentes celulares (SCANDALIOS, 2002); WONG et al., 2006). Nos processos de fagocitose de micro-organismos patogênicos as células do sistema imunológico também produzem ROS e a capacidade do patógeno de se proteger destas moléculas pela formação de antioxidantes determina o curso da infecção (GILES et al., 2006). Uma das alternativas encontradas por micro-organismos é a produção de enzimas cobre/zinco superóxido dismutases, enzimas cobre-dependentes que estão presente na maioria das células humanas, bem como em células fúngicas, protegendo o patógeno dos danos da oxidação, causados pela defesa do hospedeiro. O cobre tem um papel antioxidante essencial através da ação da superóxido dismutase contra o estresse oxidante, ajudando a neutralizar os radicais livres que poderiam causar danos celulares graves. Experimentos realizados com uma cepa virulenta de Salmonella entérica identificaram que a mesma durante o processo de infecção, produzia duas $\mathrm{Cu} / \mathrm{Zn}$-superóxido dismutase (SODCI e SODCII), para reforçar os mecanismos de defesa contra as barreiras impostas pelo hospedeiro (WOOD e THIELE, 2008).

O cobre também é importante para as lacases que são enzimas cobre-dependentes (multicobre oxidases), envolvidas na via de biossíntese de melanina em fungos, sendo dependentes de cobre para sua atividade. É descrito que a síntese de melanina é regulada por cobre, ferro, e baixas concentrações de glicose (ALSPAUGH et al., 1997; WALTON et al., 2005). Walton e colaboradores (2005) analisaram a mudança de fenótipo de 19 mutantes de $C$. neoformans, com o objetivo de identificar genes envolvidos na biossíntese de melanina. Dentre os genes mutados, encontraram-se homólogos para os genes ccc2 (transportador de cobre) e para a metalochaperona atx1. Os mutantes foram analisados após a adição de $\mathrm{CuSO}_{4}$ exógeno ou após a remoção dos íons de cobre e ferro do meio com um quelante específico. Os resultados mostraram que na adição de cobre, todos os genes mutantes foram capazes de produzir melanina e durante a remoção de cobre nenhum mutante foi capaz de sintetizar melanina, sugerindo que, assim como em humanos, a homeostase do cobre também é requerida em fungos e que as lacases, o transportador CCC2 e a metalochaperona ATX1, poderiam atuar entregando íons cobre para ferro oxidases.

Outra importante enzima cobre-dependente, é a cobre amino oxidase (CAO - Copper amine oxidase - EC 1.4.3.6.), grupo de enzimas que contêm cobre e foram identificadas em bactérias, leveduras, plantas e animais. Ainda pouco se sabe sobre as suas funções biológicas, porém existem evidências do seu envolvimento no metabolismo ou desintoxicação de xenobióticos, na oxidação 
de diversos substratos aminas, fornecendo fontes de carbono e nitrogênio para o crescimento celular, principalmente de fungos (SAMUELS e KLINMAN, 2005). Foram demonstrados que CAOs apresentam um único íon cobre por monômero (LALIBERTÉ e LABBÉ, 2005). Estudos realizados por Peter e colaboradores (2008), demonstraram que uma mutação sítio dirigida em três resíduos de histidina na região amino terminal da CAO1 de Schizosaccharomyces pombe, afetou a atividade da enzima e a transcrição dos genes ctr4, ctr5 e cuf1, todos envolvidos no metabolismo de cobre, sugerindo que CAO1 exige a presença dos mesmos funcionalmente ativos.

\section{A Influência do Cobre no Metabolismo Celular e Virulência}

Para melhor entender a resposta de fungos a condições de estresse ao cobre, estudos tem sido conduzidos com o intuito de elucidar a importância e os mecanismos utilizados pelos fungos para suportar a ausência ou excesso desses íons. Exemplo desse tipo de trabalho foi o realizado por Rustici e colaboradores (2007) em S. pombe e em S. cerevisiae. Os resultados obtidos indicam um padrão de transcrição diferenciado durante o crescimento do fungo em condições de depleção de cobre. Dentre os genes diferencialmente transcritos nessas circunstâncias estão àqueles envolvidos na captura de cobre e genes envolvidos no processo de respiração celular, provavelmente pela dependência de cobre como cofator de enzimas envolvidas nesse mecanismo.

Estudos de perfis de expressão gênica de patógenos têm sido utilizados para a elucidação de estratégias de adaptação, sobrevivência e virulência de micro-organismos durante o processo infeccioso. Com o propósito de identificar genes possivelmente envolvidos na adaptação e sobrevivência do fungo termodimórfico Paracoccidioides brasiliensis no hospedeiro durante a infecção, Bailão e colaboradores (2006), utilizaram a técnica de Análise de Diferença Representacional de cDNA (cDNA-RDA) para identificar genes induzidos durante o processo infectivo e em condições que mimetizam a via hematogênica de disseminação fúngica. Sendo o transcrito ctr3 (codificante para um transportador de cobre de alta afinidade) identificado como um dos cDNAs mais abundantes em células leveduriformes derivadas de infecção em fígado de camundongos, o que reforça o possível papel de CTR3 no processo infectivo do patógeno avaliado (COSTA et al., 2007).

Sendo também sugerido que o fungo $P$. brasiliensis não seja capaz de captar ferro na forma insolúvel, o qual deve ser inicialmente solubilizado por conversão para a forma ferrosa pela redutase férrica codificada pelo gene fre2. Quando a disponibilidade de ferro é baixa, como supostamente ocorre nos tecidos do hospedeiro, $P$. brasiliensis utilizaria um sistema de captação de alta afinidade que compreende uma permease de membrana ZRT1 (high-affinity zinc/iron transporter) e uma oxidase multi-cobre, ambas identificadas em análises transcricionais. Dessa maneira, a captação redutiva de ferro requereria também a captação de cobre mediada por uma permease codificada pelo gene ctr3, a exemplo de outros microrganismos (BAILÃO et al., 2006; COSTA et al., 2007). 
Quando células de $P$. brasiliensis ( $P b 03$ ) foram cultivadas na presença de plasma humano inativado, foi identificada a presença de hemopexina e ceruloplasmina ligadas à parede celular deste fungo. A hemopexina liga firmemente a grupos heme e elimina o heme livre, a fim de proteger o corpo dos danos oxidativos. Ceruloplasmina é responsável por carregar cerca de $70 \%$ do cobre total no plasma humano, e exibe uma atividade de oxidase dependente de cobre, que possivelmente oxida $\mathrm{Fe}^{2+}$ em $\mathrm{Fe}^{3+}$, participando assim no transporte de ferro (Longo et al., 2013).

\section{CONSIDERAÇÕES FINAIS}

As relações bioquímicas e moleculares existentes entre a homeostase de cobre, ferro e outros micronutrientes ainda não são bem estabelecidas em fungos, assim como o transporte e regulação da utilização de cobre. No geral, os mecanismos reguladores influenciando o transporte e a manutenção dos níveis desse micronutriente são pouco conhecidos em fungos patogênicos. Ressalte-se que o cobre, um elemento essencial para a maioria dos organismos, funciona como um sinal regulador para a expressão de determinantes de virulência em muitos patógenos procariotos e eucariotos. Em vários patógenos o excesso de cobre, ferro, zinco e outros micronutrientes promovem a infecção e a progressão da doença. Muitos organismos patogênicos desenvolveram estratégias complexas para a aquisição de cobre nos sítios de infecção e a competição entre o hospedeiro e o patógeno por micronutrientes é um aspecto crítico de muitas doenças infecciosas, causadas por fungos.

Com base nos resultados obtidos na literatura científica, fica evidente que os fungos patogênicos possuem uma rede de genes regulados por privação de cobre e ferro, especialmente genes já descritos na literatura como relacionados com virulência e patogenicidade. Nessa classe de genes incluem-se tanto proteínas transportadoras de cobre (CTRs), assim como todos os outros genes que participam na manutenção da homeostase de cobre no meio intracelular. Muitos são os papéis desempenhados pelo íon cobre na biologia e mecanismos envolvidos no processo de virulência em micro-organismos patogênicos. O conhecimento da regulação da homeostase de cobre permanece escasso e, portanto, apresenta-se como um assunto crescente.

\section{REFERÊNCIAS}

ALSPAUGH JA, PERFECT JR, HEITMAN J. Cryptococcus neoformans mating and virulence are regulated by the G-protein alpha subunit GPA1 and cAMP. Genes Dev 11: 3206-3217. 1997.

BAILÃO, A. M., SCHRANK, A., BORGES, C. L., DUTRA, V., MOLINARI-MADLUM, E. E. W. I., FELIPE, M. S. S., MENDES-GIANNINI, M. J., MARTINS, W. S., PEREIRA, M. E SOARES, C. M. A. Differential gene expression by Paracoccidioides brasiliensis in host interaction conditions: Representational difference analysis identifies candidate genes associated with fungal pathogenesis. Microbes Infect 8 (12-13): 268697. 2006.

BEAUDOIN, J., LABBÉ, S. Copper induces Cytoplasmic Retetion of Fission Yeast Transcription Factor Cuf1. Eukaryot cell. 5 (2):277-292. 2006. 
BEAUDOIN, J., LABBÉ, S. Crm1-mediated nuclear export of the Schizosaccharomyces pombe transcription factor Cuf1 during a shift from low to high copper concentrations. Eukaryot cell. 6(5): 764-75. 2007.

BELLEMARE DR, SHANER L, MORANO KA, BEAUDOIN J, LANGLOIS R, LABBE S. Ctr6, a vacuolar membrane copper transporter in Schizosaccharomyces pombe. J. Biol. Chem. 277, 46676-46686. 2002.

COSTA, M., BORGES, C. L., BAILAO, A. M., MEIRELLES, G. V., MENDONCA, Y. A., DANTAS, S. F., DE FARIA, F. P., FELIPE, M. S., MOLINARI-MADLUM, E. E., MENDES-GIANNINI, M. J., FIUZA, R. B., MARTINS, W. S., PEREIRA, M. AND SOARES, C. M. Transcriptome profiling of Paracoccidioides brasiliensis yeast-phase cells recovered from infected mice brings new insights into fungal response upon host interaction. Microbiology 153(Pt 12): 4194-207. 2007.

DANCIS, A., YUAN, D. S., HAILE, D., ASKWITH, C., EIDE, D., MOEHLE, C., KAPLAN, J. AND KLAUSNER, R. D. Molecular characterization of a copper transport protein in S. cerevisiae: an unexpected role for copper in iron transport. Cell 76(2): 393-402.1994.

EIDE, D. J. Multiple Regulatory Mechanisms Maintain Zinc Homeostasis in Saccharomyces cerevisiae. J Nutr 133(5 Suppl 1):1532-5. 2003.

GEORGATSOU, E., MARVROGIANNIS, L.A., FRANGIADAKIS, G. S., ALEXANDRAKI, D. The yeast Fre1p/Fre2p cupric reductases facilitate copper uptake and are regulated by the coper-modulated Mac1p activator. J. Biol. Chem. 272:13786-13792. 1997.

GILES, S. S., STAJICH, J. E., NICHOLS, C., GERRALD, Q. D., ALSPAUGH, J. A., DIETRICH, F. AND PERFECT, J. R. The Cryptococcus neoformans catalase gene family and its role in antioxidant defense. Eukaryot Cell 5(9): 1447-59. 2006.

HAMER, D. H., Metallothionein. Annu. Rev. Biochem. 55: 913-951. 1986.

HAMER, D. H., THIELE, D. J., LEMONTT, J. E. Function and autoregulation of yeast copper thionein. Science, 228:685-690. 1985.

JUNG, W. H., SHAM, A., WHITE, R. AND KRONSTAD, J. W. Iron regulation of the major virulence factors in the AIDS-associated pathogen Cryptococcus neoformans. PLoS Biol 4(12): 410. 2006.

KIM, B. E., T. NEVITT, e D. J. THIELE. Mechanisms for copper acquisition, distribution and regulation. Nat. Chem. Biol. 4:176-185. 2008.

LALIBERTÉ, J., e S. LABBÉ. Mechanisms of copper loading on the Schizosaccharomyces pombe copper amine oxidase 1 expressed in Saccharomyces cerevisiae. Microbiology 152:2819-2830. 2005.

LONGO L, NAKAYASU E, MATSUO A, DA SILVA RP, SOBREIRA T, VALLEJO M, GANIKO L, ALMEIDA I, PUCCIA R. Identification of human plasma proteins associated to the cell wall of the pathogenic fungus Paracoccidioides brasiliensis. FEMS Microbiol Lett. 2013.

MARVIN, M E., WILLIAMS, P H., CASHMORE, A M. The Candida albicans CTR1 gene encodes a functional copper transporter. Microbiology. 149:1461-1474. 2003.

MARVIN, M. E.; MASON, R. P.; CASHMORE A. M. The CaCTR1 gene is required for high-affinity iron uptake and is transcriptionally controlled by a copper-sensing transactivator encoded by CaMAC 1 . Microbiology, 150, 2197-2208. 2004.

ONODERA, J. e OHSUMI, Y. Autophagy is required for maintenance of amino acid levels and protein synthesis under nitrogen starvation. J Biol Chem 280: 31582-86. 2005.

PAPANIKOLAOU, G., PANTOPOULOS, K. Iron metabolism and toxicity. Toxicol Appl Pharm 202: 199211. 2005.

PEÑA, M.M., PUIG, S. e THIELE, D.J. Characterization of the Saccharomyces cerevisiae high affinity copper transporter Ctr3. J. Biol. Chem. 275, 33244-33251. 2000. 
PETER C., LALIBERTÉ J., BEAUDOIN J., AND LABBÉ S. Copper Distributed by Atx1 Is Available to Copper Amine Oxidase 1 in Schizosaccharomyces pombe. Eukaryotic Cell, October, p. 1781-1794, Vol. 7, No. 10. 2008.

PETRIS, M.J. The SLC31 (CTR) copper transporter family. Eur J Physiol 447: 752-755. 2004.

PUIG, S., LEE, J., LAU, M. e THIELE, D.J. Biochemical and genetic analyses of yeast and human high affinity copper transporters suggest a conserved mechanism for copper uptake. J. Biol. Chem. 277, 2602126030. 2002.

REES, E. M. e THIELE, D. J. From aging to virulence: forging connections through the study of copper homeostasis in eukaryotic microorganisms. Curr Opin Microbiol 7, 175-184. 2004.

REES, E.M. e THIELE, D.J. Identification of a vacuole-associated metalloreductase and its role in Ctr2mediated intracellular copper mobilization. J. Biol. Chem. 282, 21629-21638. 2007.

RICHIE, D. L e ASKEW D.S. Autophagy a role in metal ion homeostasis? Landes Bioscience 4:1, 115117.2008.

RUSTICI, G., BAKEL, H. V., LACKNER, D. H., HOLSTEGE, F. C., WIJMENGA C., BAHLER, J., BRAZMA, A. Global transcriptional responses of fission and budding yeast to changes in copper and iron levels: a comparative study. Physiol. Genomics. 11;22(3):356-67. 2005.

RUTHERFORD J. C. BIRD , A. J. Metal-Responsive Transcription Factors That Regulate Iron, Zinc, and Copper Homeostasis in Eukaryotic Cells. Eukaryotic Cell, 1-13, Vol. 3, N. 1. 2004.

SAMUELS, N. M., e J. P. KLINMAN. 2,4,5-Trihydroxyphenylalanine quinone biogenesis in the copper amine oxidase from Hansenula polymorpha with the alternate metal nickel. Biochemistry 44:14308-14317. 2005.

SCANDALIOS , J. G. The rise of ROS. Trends Biochem. Sci. 27 - 483-486. 2002.

THEIL, E. C., R. S. EISENSTEIN. Combinatorial mRNA regulation: iron regulatory proteins and iso-ironresponsive elements (Iso-IREs). J. Biol. Chem. 275:40659-40662. 2000.

VAN HO, A., MCVEYWARD, D. e KAPLAN J. Transition metal transport in Yeast. Annu. Rev. Microbiol. 56:237-61. 2002.

WALTON, F. J., IDNURM, A. e HEITMAN, J. Novel gene functions required for melanization of the human pathogen Cryptococcus neoformans. Mol Microbiol 57(5): 1381-96. 2005.

WONG, P.C; WAGGONER, D; SUBRAMANIAM, JR; ROTHSTEIN, J; GITLIN, JD. Copper chaperone for superoxide dismutase is essential to activate mammalian $\mathrm{Cu} / \mathrm{Zn}$ superoxide dismutase. Proc. Natl. Acad. Sci. USA 97, 2886-2891. 2006.

WOOD L.K, THIELE D.J, et al. Transcriptional activation in yeast in response to copper deficiency involves copper-zinc superoxide dismutase. J Biol Chem. 284/1(404-13), 0021-9258. 2009.

WOODACRE, A., MASON, R. P. JEEVES, R. E., e CASHMORE, A. M. Copper-dependent transcriptional regulation by Candida albicans Mac1p. Microbiology 154, 1502-1512. 2008. 